\title{
Maternal Body Mass Index Is Strongly Associated with Children Z-Scores for Height and BMI
}

\author{
Pushpa Lata Tigga and Jaydip Sen \\ Department of Anthropology, University of North Bengal, P.O. NBU, Raja Rammohunpur, Darjeeling, West Bengal 734 013, India \\ Correspondence should be addressed to Jaydip Sen; jaydipsen@rediffmail.com
}

Received 29 July 2016; Revised 30 September 2016; Accepted 3 October 2016

Academic Editor: Kaushik Bose

Copyright ( 2016 P. L. Tigga and J. Sen. This is an open access article distributed under the Creative Commons Attribution License, which permits unrestricted use, distribution, and reproduction in any medium, provided the original work is properly cited.

\begin{abstract}
Introduction. Undernutrition continues to be a major public health problem throughout the developing world, particularly in subSaharan Africa and Asia including India. Limited studies suggest associations between maternal body mass index (BMI) and child nutritional status. The present study aims to determine the relationship between maternal BMI and children nutritional status. Methods. The study was conducted among 246 mothers who had given birth to single children $(n=246)$ and belonged to the Proto-Australoid population of North Bengal, India. The anthropometric measurements of height and weight were recorded following standard procedures. Overall body composition was evaluated using BMI. Result. The results showed that overall mean BMI among mothers was $20.63 \pm 2.53 \mathrm{~kg} / \mathrm{m}^{2}$, while those among boys and girls were $15.19 \pm 1.62 \mathrm{~kg} / \mathrm{m}^{2}$ and $14.86 \pm 1.37 \mathrm{~kg} / \mathrm{m}^{2}$ $(p<0.001)$, respectively. The BMI of mothers were significantly and highly correlated with HAZ (0.709) and BMIZ (0.748) $(p<0.001)$ of children. These are indicative of a strong genetic component between maternal and child anthropometry. Conclusion. The results indicate significant associations between mothers' and children's nutritional status. Assessments of body composition and nutritional status using BMI, especially among mothers and their children, are recommended.
\end{abstract}

\section{Introduction}

The nutritional status of any individual is his/her health as dictated by the quality of nutrients consumed and the body's ability to utilize them for its metabolic needs. The World Health Organization (WHO) believes that the ultimate objective of nutritional assessments is overall improvement in the quality of human health [1]. Undernutrition is considered to be a major public health issue in many of the developing countries such as India. Among children, it is a principal cause of increased ill-health, premature mortalities and morbidities, and long-lasting physiological effects $[2,3]$. Undernutrition has also been observed to have significant adverse health effects among those children who survive to adulthood and it is the largest contributor to global burden of disease [4]. The underlying causes of undernutrition vary from poverty and low levels of education to poor access to health services [3, 5-8]. India has the highest occurrence of child undernutrition in the world and it has been estimated that more than half of the Indian children remain undernourished [3]. It has also been reported that the country has more than 47 million stunted children and that nearly $20 \%$ of children are born with low birth weight $[9,10]$. Therefore, nutritional assessments of children are a priority area in the country and have potential roles to play in formulating developmental strategies and intervention programmes in the same.

Undernutrition among children has been routinely assessed using the technique of anthropometry. This technique is usually preferred because it is noninvasive and relatively simple and it can be easily recorded and interpreted. Usually, researchers have utilized the indices of body mass index (BMI), stunting, wasting, and underweight to assess child nutritional status. A prolific number of studies are present in the existing literature in this aspect. Recent studies include those of Gashu et al. [11], Murakami and Livingstone [12], Sinharoy et al. [13], and Zhang et al. [14].

Maternal malnutrition is a major predisposing factor for morbidity and mortality among women of the developing countries. The causes include inadequate food intake, poor nutritional quality of diets, frequent infections, and short interpregnancy intervals. The consequences of poor maternal 
nutritional status are reflected in low pregnancy weight gain and high infant and maternal morbidity and mortality. It was observed by Goudet et al. [15] that maternal nutritional status remains an important determinant of child health and nutritional status. As a result, one of the major aims of nutritional research is to understand the relationship between maternal and child nutritional status using anthropometry [16]. Recent studies have shown that maternal nutritional status was related to several adverse outcomes in the offspring that also included nutritional outcomes among the latter [17-21]. Studies have shown maternal BMI to be closely associated with child nutritional status [22, 23]. Maternal underweight was another significant factor involved [24]. Maternal nutritional status has also an important role to play in birth weight of infants $[25,26]$.

The WHO has estimated that, in the year 2012, a total of 6.60 million deaths occurred among children aged under 5 years (usually referred to as preschool children) and that undernutrition was identified to be the principal underlying cause of mortality in an estimated $45.00 \%$ of all deaths among children [27]. Preschool children have been specifically studied because their health status is a sensitive indicator of overall community health, particularly among disadvantaged groups in populations $[28,29]$. This group is also nutritionally vulnerable due to their easy susceptibility to undernutrition and infection $[30,31]$. They require a high supply of nutrients since they are usually very active and their growth rate is rapid. Moreover, during this period, nutritional diseases in the form of kwashiorkor, marasmus, anaemia, and xerophthalmia are not uncommon [32-34]. Preschool children call for focused attention in India as because the country has the world's highest percentage of undernourished children [35]. In the year 2015, it was reported that globally there were 5.90 million deaths of children under the age of 5 years, of which 1.20 million (20\%) occurred in India alone [36]. Currently, the country has an under 5 mortality rate of 48 per 1000 live births [36]. A large number of published literatures are available on the nutritional status of children aged less than 5 years using anthropometry. Here, the studies of Biswas and Bose [37], Mandal et al. [38], Mathad et al. [39], Sen and Mondal [40], Patel et al. [41], Anuradha et al. [42], and Chatterjee et al. [43] are mentionable.

Contemporary India is composed of a sizable number of ethnic and indigenous elements having enormous amounts of ethnic and genetic diversity. With a population of more than 84 million individuals, India has the largest number of indigenous people in the world and the country now includes diverse tribal, nontribal, and caste populations [44, 45]. Studies have focused on assessments of nutritional status among preschool children belonging to different indigenous and tribal populations of the country. Here, the studies among the Lodha [46], Sahariya [47], Proto-Australoid tribals [4850], Chenchu [51], and tribals from Assam and other parts of north-east India $[52,53]$ are mentionable. Other notable studies among preschool children belonging to the tribal populations of the country include those of Rao et al. [54], Bhattacharyya and Sarkar [55], and Meshram et al. [56].

However, Indian studies on the association between maternal nutritional status parameters and child nutritional status using anthropometry appear to be scarce in the existing literature. There are some studies on the relation between such maternal nutritional parameters and birth weight [5760]. Given the above, the present study was undertaken to determine the association between maternal BMI and nutritional status of children belonging to a tribal population of the country.

\section{Material and Method}

2.1. Nature of Subjects and Area. The present study was carried out among preschool children aged 2-5 years who frequented 16 centers of the Integrated Child Development Scheme (ICDS) located in the rural areas of Sukna, Mohargaon, Matigara, and Nishchintapur under Siliguri subdivision of the district of Darjeeling. The children covered in the present study belonged to the Proto-Australoid Tribal Population. Initially, it was the British who were instrumental in bringing individuals belonging to the Proto-Australoid tribal communities (e.g., Santal, Oraon, and Munda) from the Chotanagpur plateau of Bihar to North Bengal in the mid-19th century to be employed as workers in the tea gardens. They are now found in a conglomerate ethnic group collectively referred to as "Tea-labourer" in North Bengal [61].

The ICDS was launched by the Government of India on 2nd of October 1975 as an experimental project in 29 rural and tribal blocks and 4 urban slums. It now includes preschool children, pregnant and lactating mothers, and women in the age group of 15 years to 44 years and is the largest national program for promotion and development of health of mother and child [48, 62]. It provides nonformal preschool education, supplementary nutrition, immunization, health check-up, referral services, nutrition, and health education to the beneficiaries. The children are also served a daily food supplementation in the form of porridge, consisting approximately of 50 grams of rice and 25 grams of lentil in the centers.

Prior to data collection, necessary permissions were taken from the ICDS centers and local Panchayets (a village level governing authority). Approval for the study was obtained from the University of North Bengal and the study has been conducted in accordance with the ethical guidelines for human experiments as laid down in the Helsinki Declaration of 2000 [63]. The participants were selected using a stratified random sampling method. Initially, mothers and children belonging to the Proto-Australoid tribal population were identified. Subsequently, those mothers having a single child were identified. Once this was accomplished, mothers having single children aged 2-5 years were selected. A total of 300 mothers and their 300 children (boys: 155; girls: 145) were approached to participate in the study. The age and ethnicity of the children were verified from both ICDS center records and birth certificates. However, 54 of them (boys: 30; girls: 24) were excluded, as their ages could not be verified or their mothers refused to participate in the study. So the final sample comprised 246 mothers who had a single child and 246 children aged $2-5$ years (boys: 124 ; girls: 122 ). All the children were free from physical deformities and were not 
suffering from any illness and/or diseases at the time of data collection. The objectives of the study were explained to either parent of the children and an informed consent was obtained from them. The data was collected during the period from June 2014 to November 2014.

2.2. Anthropometric Measurements Recorded. The anthropometric measurements of height and weight were recorded following standard procedures of Weiner and Lourie [64]. Height of mothers and their children was recorded with the help of an anthropometric rod to the nearest $0.10 \mathrm{~cm}$. Their weights were recorded in minimum clothing and weight with bare feet was taken using a portable weighing scale to the nearest $0.50 \mathrm{~kg}$. Intraobserver and interobserver technical errors of the measurement (TEM) were calculated for testing reliability of the data following the method of Ulijaszek and Kerr [65]. For calculating TEM, height and weight were recorded from 50 children other than those selected for the study by both authors (PT and JS).

The TEM was calculated using the following equation:

$$
\mathrm{TEM}=\sqrt{ } \frac{\Sigma D^{2}}{2 N},
$$

where $D$ is difference between the measurements and $N$ is number of individuals.

The coefficient of reliability $(R)$ was subsequently calculated from TEM using the following equation:

$$
R=\left\{1-\frac{(\mathrm{TEM})^{2}}{\mathrm{SD}^{2}}\right\},
$$

where SD is standard deviation of the measurements.

Very high values of $R(>0.975)$ were obtained for both intra- and interobserver TEM and these values were observed to be higher than the cutoff value of 0.95 as recommended by Ulijaszek and Kerr [65]. Hence, the measurements recorded by both PT and JS were considered to be reliable and reproducible. Subsequently, height and weight in the course of the present study were recorded by one of the authors (PT).

\subsection{Prevalence of Undernutrition among Children. Undernu-} trition among children was documented by calculating $Z$ score values using the available age and sex-specific WHO child growth reference values [66]. $Z$-scores were calculated using the WHO Anthro Plus calculator. The values of height-for-age $Z$-score (HAZ), weight-for-age $Z$-score (WAZ), weight-for-height $Z$-score (WHZ), and body mass index for $Z$-score (BMIZ) between " -2 to -3 " and " $<-3$ " were considered as moderately and severely undernourished, respectively. The BMI was calculated following the internationally accepted standard equation of WHO [67]:

$$
\mathrm{BMI}=\frac{\text { Weight }(\mathrm{kg})}{\text { Height }^{2}(\mathrm{~m})} \text {. }
$$

2.4. Prevalence of Undernutrition among Mothers. The prevalence of undernutrition among mothers was assessed following the international BMI cutoff points for CED as proposed by $\mathrm{WHO}[67]$.
TABLE 1: Descriptive statistics (mean \pm SD) of age and anthropometric variables related to nutritional status of mothers and their children.

\begin{tabular}{lcc}
\hline Variable & $N$ & Mean/SD \\
\hline $\begin{array}{l}\text { Mothers' variables } \\
\text { Age }\end{array}$ & & \\
Height & 246 & $31.85 \pm 5.95$ \\
Weight & 246 & $144.98 \pm 4.17$ \\
BMI & 246 & $43.25 \pm 4.58$ \\
Children's variables & 246 & $20.63 \pm 2.53$ \\
Age & & \\
Height & 246 & $4.29 \pm 1.29$ \\
Weight & 246 & $89.89 \pm 10.14$ \\
BMI & 246 & $12.18 \pm 2.37$ \\
\hline
\end{tabular}

2.5. Statistical Analysis. The data was statistically analyzed using Statistical Package for Social Sciences (SPSS version 17.0). One way analysis of variance (ANOVA) was done to assess age and sex-specific mean differences in anthropometric variables. Correlation analysis was utilized to assess correlation among mother's BMI and child nutritional parameters. Stepwise regression analysis was utilized to assess the association of mother's BMI (independent) on children's $Z$-scores (dependent). The predictor variable of mother's BMI was used in this model. The values of $p<0.05$ and $p<0.001$ were considered to be statistically significant.

\section{Results}

3.1. Descriptive Statistics of the Data. Overall mean and standard deviation (SD) of mothers and their children was depicted in Table 1. Among children, mean \pm SD of age, height, weight, and BMI were $4.29 \pm 1.29$ years, $89.89 \pm$ $10.14 \mathrm{~cm}, 12.18 \pm 2.37 \mathrm{~kg}$, and $15.03 \pm 1.51 \mathrm{~kg} / \mathrm{m}^{2}$, respectively. Among mothers, the respective values were $31.85 \pm 5.95$ years, $144.98 \pm 4.17 \mathrm{~cm}, 43.25 \pm 4.58 \mathrm{~kg}$, and $20.63 \pm 2.53 \mathrm{~kg} / \mathrm{m}^{2}$.

3.2. Prevalence of Different Grades of Undernutrition (CED) among Mothers Based on BMI $(n=246)$. Prevalence of CED among mothers was very high (Table 2). Majorities of them were suffering from CED Grade II (68.70\%), followed by those affected by CED Grade III $(29.03 \%)$ and finally by those affected by CED Grade I (2.01\%). Less than $0.50 \%$ of them exhibited normal BMI values.

\subsection{Age and Sex-Specific Prevalence of Undernutrition among} the Children. The age and sex-specific prevalence of undernutrition among boys and girls are shown in Table 3. Among boys, overall mean \pm SD of height, weight, and BMI were $88.91 \pm 10.57 \mathrm{~cm}, 12.07 \pm 2.56 \mathrm{~kg}$ and $15.19 \pm 1.62 \mathrm{~kg} / \mathrm{m}^{2}$, while, among girls, the respective values were $90.88 \pm 9.61 \mathrm{~cm}$, $12.29 \pm 2.15 \mathrm{~kg}$, and $14.86 \pm 0.37 \mathrm{~kg} / \mathrm{m}^{2}$. Among girls, mean height and weight exhibited an increasing trend except in case of BMI which was lower than that shown by boys. Using, ANOVA statistically significant differences $(p<0.001$ and 
TABLE 2: Different grades of undernutrition (CED) among mothers based on BMI.

\begin{tabular}{lcc}
\hline CED & BMI kg/m $\mathrm{m}^{2}$ & Number of mothers \\
\hline Grade III & BMI $<16.00$ & $43(17.50)$ \\
Grade II & BMI 16.00-16.99 & $11(4.50)$ \\
Grade I & BMI 17.00-18.49 & $2(8.00)$ \\
Normal & Above $18.50-24.9$ & $177(72.00)$ \\
Overweight & $25.0-29.9$ & $13(5.30)$ \\
Total & & $246(100)$ \\
\hline
\end{tabular}

Figure in parenthesis indicates percentage.

$p<0.05)$ were observed between sexes with respect to height, weight, BMI, HAZ, WAZ, WHZ, and BMIZ.

Lower values of HAZ, WAZ, WHZ, and BMIZ indicated whether the children were stunted, underweight, and wasted. Among boys, $\mathrm{HAZ} Z$-score was $-4.21 \pm 1.35,-2.50 \pm 2.69$, $-1.90 \pm 1.08$, and $-2.34 \pm 1.48$ in the individuals ages, respectively. Among girls, the corresponding values were $-2.73 \pm 1.66,-3.09 \pm 1.27,-1.33 \pm 3.22$, and $-1.92 \pm 2.01$ which were lower than boys. $F$-values were observed to be statistically significant $(p<0.001)$ among them. In case of WAZ $Z$-scores, the values for boys were $-2.69 \pm 2.70,-1.54 \pm$ $2.19,-1.39 \pm 3.03$, and $-0.47 \pm 3.03$ for the corresponding ages, which were higher than the corresponding values for girls. $F$-values were also statistically significant $(p<0.001)$. The BMIZ among boys were $3.78 \pm 1.14$ for 2 years, $-2.25 \pm 0.68$ for 3 years, $-1.82 \pm 0.71$ for 4 years, and $-2.11 \pm 1.34$ for 5 years. Among girls, the corresponding values were $-3.21 \pm 1.19$, $-2.61 \pm 0.41,-1.79 \pm 0.67$, and $1.06 \pm 0.76$, respectively. The age specific differences in prevalence of different categories of undernutrition were observed to be statistically significant $(p>0.001)$ among boys and girls, except WAZ and WHZ among boys.

3.4. Pearson's Correlation Coefficients between Mother's BMI and Child Z-Score Indices. The Pearson's correlation coefficients between maternal BMI and child $Z$-score indices (HAZ, WAZ, WHZ, and BMIZ) were positive and are shown in Table 4 . The correlation coefficients were $0.608,0.152,0.195$, and 0.772 , respectively.

3.5. Stepwise Logistic Regression among Maternal Anthropometric Characters (Independent Variables) with Children ZScore Indices. Using a stepwise logistic regression, dependent variables (HAZ, WAZ, WHZ, and BMIZ of children) were fitted for mother's BMI and the results are depicted in Table 5. The results reveal that BMI was an important predictor variable of HAZ, WAZ, and BMIZ. Maternal BMI (Model 1) explained for $70.90 \%, 5.10 \%$, and $74.80 \%$ of variations in these three dependent variables except for WHZ (28.60\%). There were significant associations between maternal BMI and children HAZ, WAZ, and BMIZ except WHZ. The associations of sex-specific mean anthropometric variable of mother's BMI and children $Z$-score are shown in Figure 1. Moreover, mean $Z$-scores of HAZ, WAZ, WHZ, and BMIZ of children had increasing trends with increased maternal BMI.
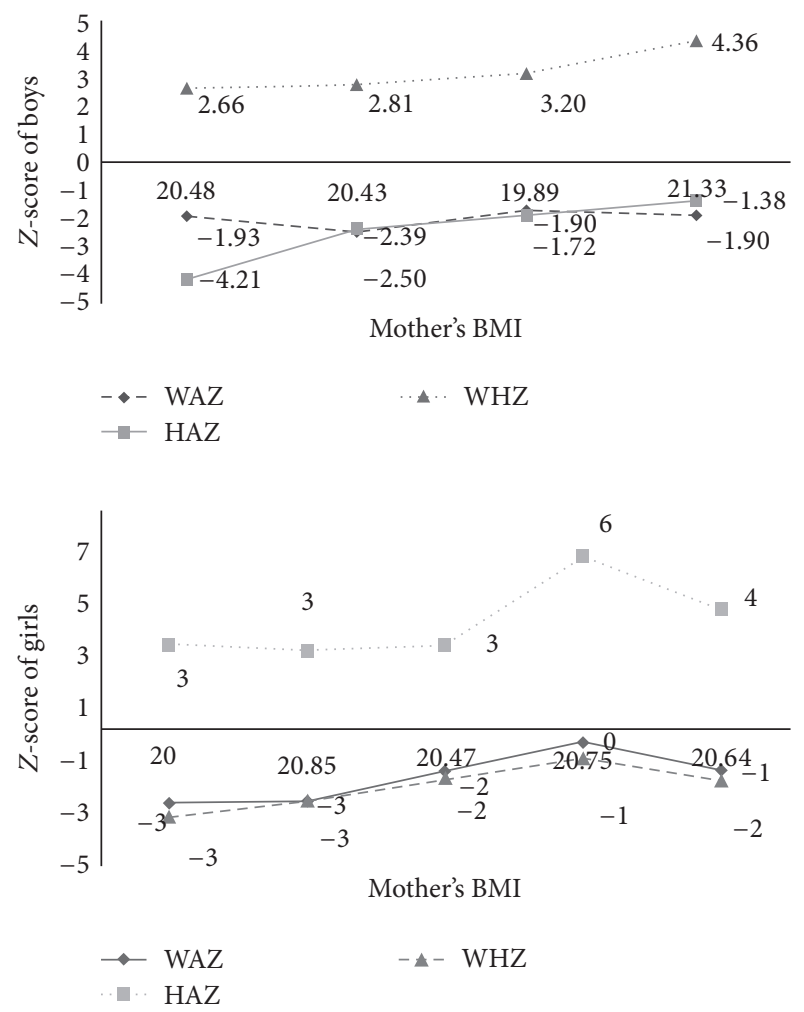

FIgURE 1: Sex-specific mean anthropometric variables of mother's BMI and children $Z$-scores.

\section{Discussion}

It is evident from Table 1 that most of the mothers included in the present study suffered from different grades of CED. Studies have consistently reported that prevalence of CED was very high among women from India. Using data from the Indian National Family Health Survey [68], Bharati et al. [69] reported an overall prevalence of CED of $31.20 \%$ among women aged 15-49 years. The prevalence of CED was high (20-39\%) among Bengalee women as observed by Bose et al. [70]. Arlappa et al. [71] observed a very high prevalence of CED (52\%) among women from Rajasthan. In a recent study, Bandyopadhyay and Sen [72] reported very high levels of CED among women working in brickfields of West Bengal. High levels of CED were reported from women belonging to different tribal populations by Bisai and Bose [73], Chakrabarty and Bharati [74], Banik [75], and Ghosh [76]. However, very recent studies from the country have reported that prevalence of CED is decreasing among women in the country. Rai [77], while utilizing data from the National Family Health Survey (NFHS) 1998-1999 and NFHS 2005-2006, documented high levels of CED among Indian women but also indicated an almost 3\% reduction in CED and a 6\% increase in overweight/obesity during 1998-2006. In another very recent study, Meshram et al. [78] observed that prevalence of CED had declined from 52\% during 197579 to $34 \%$ during $2011-12$.

The present study enabled direct evaluation of association between mother's anthropometrics characteristic and child 


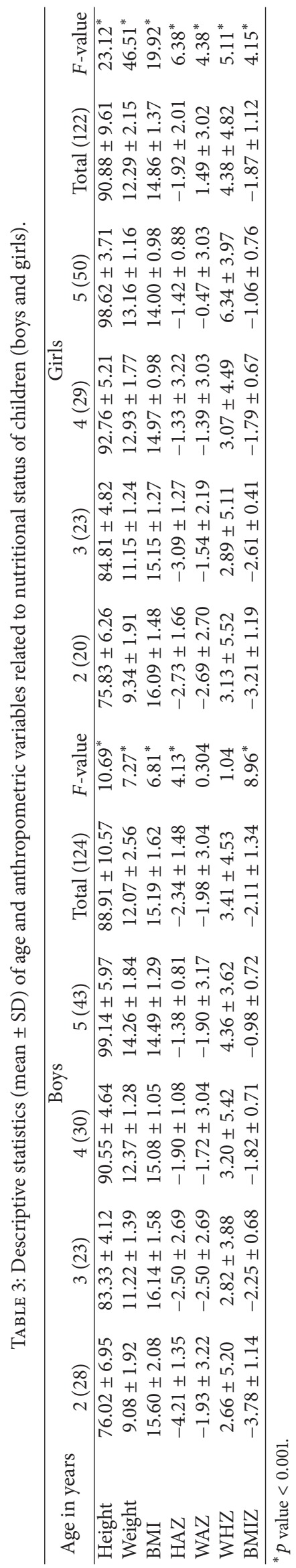


TABLE 4: Pearson's correlation between maternal BMI and child $Z$ scores.

\begin{tabular}{lc}
\hline Variables & $r$ \\
\hline Mother's BMI versus HAZ Z-score & $0.608^{* *}$ \\
Mother's BMI versus WAZ Z-score & $0.152^{*}$ \\
Mother's BMI versus WHZ Z-score & $0.195^{* *}$ \\
Mother's BMI versus BMIZ Z-score & $0.772^{* *}$ \\
${ }^{* *} p$ value $<0.001 ;{ }^{*} p$ value $<0.05$. &
\end{tabular}

${ }^{* *} p$ value $<0.001 ;{ }^{*} p$ value $<0.05$.

nutritional status. Significant associations between maternal BMI and children nutritional status were observed. India is currently in the midst socioeconomic, demographic, nutritional, and epidemiological transition and still undernutrition continues to affect large segments of the population. The early detection and effective management of current energy deficit as assessed by mother's BMI may reduce increased susceptibility to undernutrition among children. It was also observed that mean $Z$-scores for WAZ, HAZ, WHZ, and BMIZ of children had increasing trends associated with an increase in maternal BMI status (Figure 1). The stepwise regression model revealed that maternal BMI was most predictive variable of HAZ, WAZ, and BMIZ (model 1) and this explained the significant variations in these three dependent variables.

Results indicated that correlations between mother's and child's anthropometry were significant. The present study also observed existence of high correlations between mother's BMI and $Z$-scores of height of child. Both these points are indicative of a strong genetic component between maternal and child anthropometry. Thus, mother's anthropometry strongly influences child's anthropometry. Studies on the association between the nutritional statuses of mothers with that of their offsprings are scarce in the exiting literature. Some studies are available in the domain of BMI between mothers and their children. There were significant associations between maternal BMI with children weight and height $Z$-score and it was observed by many researchers (e.g., [79]) that an increase in BMI status was associated with a lower rate of childhood undernutrition. It was noted more than twenty years ago by Rahman et al. [80] that a child's nutritional status, as indicated by weight-for-age (as a percentage of NCHS median), was associated with BMI of mother $(p<0.001)$. Islam et al. [81] in a study from Bangladesh showed that mothers who were underweight were 2.5 times more likely to have underweight children. Santos et al. [82] in a Chilean study observed direct correlation $(p<0.001)$ between children's BMI $Z$-score and their mothers' BMI, both among boys (Spearman rho $=0.26)$ and girls $(r h o=0.30)$. In a recent study, Kulasekaran [83] reported that women with poorer nutritional status, as indicated by BMI, had registered higher risk of severe thinness (height-for-age) and severe underweight (weight-for-age) (27.10\% and $23.30 \%$, resp.) among their children. The study also reported that severe wasting (weight-for-height) in children was also associated with mothers' BMI. In yet another recent publication, Negash et al. [21] observed that HAZ was positively associated with maternal height. In another very recent study, Fleten et al. [84] reported that maternal BMI $(r=0.16 ; p<0.05)$ was correlated with WHZ of children while maternal height $(r=$ $0.20 ; p<0.05)$ was correlated with HAZ of children. Significant positive association between maternal BMI and children BMI was also noted by Ajslev et al. [85] and Ray [86].

The present study has confirmed the earlier suggestion that anthropometric measurements were useful in identifying mothers at high risk of delivering low birth weight newborns [58]. Anthropometric measurements recorded on children aged 2 years showed that boys have higher metric values in case of height, HAZ $Z$-score, and BMIAZ $Z$-score than girls. But mean weight, BMI, WAZ $Z$-score, and WHZ $Z$-score of girls increased. Net increase in BMI, HAZ, WAZ, and BMIZ in case of boys aged 4 years in case of except height and weight over that of girls was noted by Rolland-Cachera et al. [87].

Possibly, it is important to note that, during infancy, the relationship between mother and child malnutrition is affected by biological consequences of maternal malnutrition during lactation. Thus, interventions by improving maternal nutritional status could have a significant role in the prevention of childhood malnutrition. One additional issue that needs to be highlighted is "adiposity rebound," which refers to the second increase in BMI during early childhood [87]. It is of concern that between-population differences in the patterns of adiposity rebound may exist, in particular, between populations in industrialized and developing countries. This may affect the estimate of obesity prevalence for children at around the age of adiposity rebound when the international BMI references based upon data collected in a particular wealthy society are used. This pattern of change in BMI means that the age of adiposity rebound inevitably predicts later BMI, as was first shown by Rolland-Cachera et al. [87]. This association between changes in BMI applies at all ages, not just at around 5 years, so the adiposity rebound should not be viewed as a critical period for obesity development. The NCHS/WHO growth references have played an important role in the past for international use in assessing child and adolescent growth and nutritional status. WHO has recently developed and recommended the use of a new international reference for infants and preschool children.

\section{Conclusions}

The results of the present study indicate a high prevalence of undernutrition among mothers and their children aged $2-5$ years. Initiatives should be taken to improve nutritional status of such children. The results showed that moderate undernutrition is more prevalent than severe undernutrition. The intervention programmes should focus on improving the nutritional status and environmental and personal hygiene of the children along with regular monitoring of their health so as to achieve their optimal growth potentials. The present study has observed the prevalence of undernutrition among children to be associated with maternal nutritional status.

\section{Competing Interests}

The authors declare that they have no competing interests. 
TABLE 5: Logistic regression analysis of maternal BMI (independent variable) with child HAZ $Z$-score, WAZ $Z$-score, WHA $Z$-score, and BMIZ Z-score.

\begin{tabular}{|c|c|c|c|c|c|c|c|}
\hline Model & Dependent variable & Independent variable & $B$ & SEB & $t$ & Sig. & Adj. $R^{2}$ \\
\hline \multirow{2}{*}{1} & \multirow{2}{*}{ HAZ } & Constant & -5.973 & 0.456 & -13.095 & $0.000^{* *}$ & \\
\hline & & (BMI) & 1.306 & 0.201 & 6.510 & 0.000 & 0.709 \\
\hline \multirow{2}{*}{1} & \multirow{2}{*}{ WAZ } & Constant & -3.269 & 1.053 & -3.103 & $0.007^{*}$ & \\
\hline & & (BMI) & 0.642 & 0.463 & 1.385 & 0.185 & 0.051 \\
\hline \multirow{2}{*}{1} & \multirow{2}{*}{ WHZ } & Constant & -0.307 & 1.217 & -0.253 & 0.804 & \\
\hline & & (BMI) & 1.494 & 0.535 & 2.792 & 0.013 & 0.286 \\
\hline \multirow{2}{*}{1} & \multirow{2}{*}{ BMIZ } & Constant & -5.675 & 0.430 & -13.185 & $0.000^{* *}$ & \\
\hline & & (BMI) & 1.357 & 0.189 & 7.168 & 0.000 & 0.748 \\
\hline
\end{tabular}

${ }^{* *} p$ value $<0.001 ;{ }^{*} p$ value $<0.05$

\section{Acknowledgments}

The authors acknowledge the help and cooperation of the ICDS centers, participants of the study, and their parents. Financial assistance of the University Grants Commission, Government of India, in the form of a Rajiv Gandhi National Fellowship (F1-17.1/17.1/2012-13/RGNF-2012-2013ST-WES-24896) is also acknowledged.

\section{References}

[1] I. Beghin, M. Cap, and B. Dujardin, A Guide to Nutritional Assessment, World Health Organization, Geneva, Switzerland, 1988.

[2] S. Nandy, M. Irvining, D. Gorden, and S. Toseil, "Poverty, child undernutrition and morbidity: new evidence from India," Bulletin of World Health Organization, vol. 83, no. 3, pp. 210-216, 2005.

[3] T. Ahmed, M. Hossain, and K. I. Sanin, "Global burden of maternal and child undernutrition and micronutrient deficiencies," Annals of Nutrition and Metabolism, vol. 61, pp. 8-17, 2012.

[4] R. E. Black, L. H. Allen, Z. A. Bhutta et al., "Maternal and child undernutrition: global and regional exposures and health consequences," The Lancet, vol. 371, no. 9608, pp. 243-260, 2008.

[5] S. Petrou and E. Kupek, "Poverty and childhood undernutrition in developing countries: a multi-national cohort study," Social Science and Medicine, vol. 71, no. 7, pp. 1366-1373, 2010.

[6] K. D. Singh, M. Alagarajan, and L. Ladusingh, "What explains child malnutrition of indigenous people of Northeast India?" PLoS ONE, vol. 10, no. 6, Article ID e0130567, 2015.

[7] A. C. Mathew, D. Das, S. Sampath, M. Vijayakumar, N. Ramakrishnan, and S. L. Ravishankar, "Prevalence and correlates of malnutrition among elderly in an urban area in Coimbatore," Indian Journal of Public Health, vol. 60, pp. 112-117, 2016.

[8] M. Z. Siddiqui and R. Donato, "Undernutrition among adults in India: the significance of individual-level and contextual factors impacting on the likelihood of underweight across subpopulations," Public Health Nutrition, vol. 12, pp. 1-12, 2016.

[9] P. Bharati, M. Pal, M. Bandyopadhyay, A. Bhakta, S. Chakraborty, and P. Bharati, "Prevalence and causes of low birth weight in India," Malaysian Journal of Nutrition, vol. 17, no. 3, pp. 301-313, 2011.

[10] M. Kader and N. K. P. Perera, "Socio-economic and nutritional determinants of low birth weight in India," North American Journal of Medical Sciences, vol. 6, no. 7, pp. 302-308, 2014.
[11] D. Gashu, B. J. Stoecker, K. Bougma, A. Adish, G. D. Haki, and G. S. Marquis, "Stunting, selenium deficiency and anemia are associated with poor cognitive performance in preschool children from rural Ethiopia," Nutrition Journal, vol. 15, article 38, 2016.

[12] K. Murakami and M. B. Livingstone, "Associations between meal and snack frequency and overweight and abdominal obesity in US children and adolescents from National Health and Nutrition Examination Survey (NHANES) 2003-2012," British Journal of Nutrition, vol. 115, no. 10, pp. 1819-1829, 2016.

[13] S. S. Sinharoy, W. P. Schmidt, K. Cox et al., "Child diarrhoea and nutritional status in rural Rwanda: a cross-sectional study to explore contributing environmental and demographic factors," Tropical Medicine and International Health, vol. 21, no. 8, pp. 956-964, 2016.

[14] J. Zhang, H. Xue, X. Cheng et al., "Influence of proximities to food establishments on body mass index among children in China," Asian Pacific Journal of Clinical Nutrition, vol. 25, pp. 134-141, 2016.

[15] S. Goudet, P. Griffths, and B. A. Bogin, "Mother's body mass index as a predictor of infant's nutritional status in the postemergency phase of a flood," Disasters, vol. 35, no. 4, pp. 701-719, 2011.

[16] C. A. Gewa, M. Oguttu, and N. S. Yandell, "Maternal nutrition in rural Kenya: health and socio-demographic determinants and its association with child nutrition," Maternal and Child Nutrition, vol. 8, no. 3, pp. 275-286, 2012.

[17] S. V. Subramanian, L. K. Ackerson, G. D. Smith, and N. A. John, "Association of maternal height with child mortality, anthropometric failure, and anemia in India," The Journal of the American Medical Association, vol. 301, no. 16, pp. 1691-1701, 2009.

[18] E. Özaltin, K. Hill, and S. V. Subramanian, "Association of maternal stature with offspring mortality, underweight, and stunting in low- to middle-income countries," The Journal of the American Medical Association, vol. 303, no. 15, pp. 1507-1516, 2010.

[19] O. Y. Addo, A. D. Stein, C. H. Fall et al., "Maternal height and child growth patterns," Journal of Pediatrics, vol. 163, no. 2, pp. 549.el-554.el, 2013.

[20] M. S. Felisbino-Mendes, E. Villamor, G. Velasquez-Melendez, and R. A. Nugent, "Association of maternal and child nutritional status in brazil: a population based cross-sectional study," PLoS ONE, vol. 9, no. 1, Article ID e87486, 2014.

[21] C. Negash, S. J. Whiting, C. J. Henry, T. Belachew, and T. G. Hailemariam, "Association between maternal and child 
nutritional status in Hula, rural Southern Ethiopia: a cross sectional study," PLoS ONE, vol. 10, no. 11, Article ID e0142301, 2015.

[22] C. N. Rachmi, K. E. Agho, M. Li, L. A. Baur, and Y. Zhang, "Stunting, underweight and overweight in children aged 2.04.9 years in indonesia: prevalence trends and associated risk factors," PLoS ONE, vol. 11, no. 5, Article ID e0154756, 2016.

[23] T. Géa-Horta, R. d. Silva, R. L. Fiaccone, M. L. Barreto, and G. Velásquez-Meléndez, "Factors associated with nutritional outcomes in the mother-child dyad: a population-based crosssectional study," Public Health Nutrition, vol. 19, no. 15, pp. 27252733, 2016.

[24] D. J. Corsi, I. Mejía-Guevara, and S. V. Subramanian, "Risk factors for child chronic undernutrition in India: estimating relative importance, population attributable risk and fractions," Social Science and Medicine, vol. 157, pp. 165-185, 2016.

[25] K. Mohammad, M. Kassab, J. Gamble, D. K. Creedy, and J. Foster, "Factors associated with birth weight inequalities in Jordan," International Nursing Review, vol. 61, no. 3, pp. 435440, 2014.

[26] O. A. Kensara and F. S. Azzeh, "Nutritional status of low birth weight infants in Makkah region: evaluation of anthropometric and biochemical parameters," Journal of Pakistan Medical Association, vol. 66, pp. 414-417, 2016.

[27] World Health Organization, Millennium Development Goals (MDGs), 2014, http://www.wh.int/mediacentre/ofactsheets/ fs290/en/index.html.

[28] E. Piwoz, S. Sundberg, and J. Rooke, "Promoting healthy growth: what are the priorities for research and action?" Advances in Nutrition, vol. 3, no. 2, pp. 234-241, 2012.

[29] N. P. Nolla, M. M. K. Sop, M. J. Mananga, T. Ekoe, and I. Gouado, "Assessment of nutritional status of preschool children in the Bangang rural community, Cameroon," International Journal of Biotechnology and Food Science, vol. 2, pp. 44-52, 2014.

[30] A. L. Rice, L. Sacco, A. Hyder, and R. E. Black, "Malnutrition as an underlying cause of childhood deaths associated with infectious diseases in developing countries," Bulletin of the World Health Organization, vol. 78, no. 10, pp. 1207-1221, 2000.

[31] K. D. J. Jones and J. A. Berkley, "Severe acute malnutrition and infection," Paediatrics and International Child Health, vol. 34, pp. S1-S29, 2014.

[32] D. Ramírez Prada, G. Delgado, C. A. Hidalgo Patiño, J. PérezNavero, and M. Gil Campos, "Using of WHO guidelines for the management of severe malnutrition to cases of marasmus and kwashiorkor in a Colombia children's hospital," Nutricion Hospitalaria, vol. 26, no. 5, pp. 977-983, 2011.

[33] V. K. Agrawal, P. Agrawal, and Dharmendra, "Prevalence and determinants of xerophthalmia in rural children of Uttarpradesh, India," Nepal Journal of Ophthalmology, vol. 5, no. 2, pp. 226-229, 2013.

[34] P. Modi, S. Nasrin, M. Hawes et al., "Midupper arm circumference outperforms weight-based measures of nutritional status in children with diarrhea," The Journal of Nutrition, vol. 145, no. 7, pp. 1582-1587, 2015.

[35] P. Sen, S. Bharati, S. Som, M. Pal, and P. Bharati, "Growth and nutritional status of preschool children in India: a study of two recent time periods," Food and Nutrition Bulletin, vol. 32, no. 2, pp. 84-93, 2011.

[36] K. K. Yadav and S. Awasthi, "The current status of communityacquired pneumonia management and prevention in children under 5 years of age in India: a review," Therapeutic Advance in Infectious Disease, vol. 3, no. 3-4, pp. 83-97, 2016.

[37] S. Biswas and K. Bose, "Effect of number of rooms and sibs on nutritional status among rural Bengalee preschool children from Eastern India," Collegium Antropologicum, vol. 35, no. 4, pp. 1017-1022, 2011.

[38] G. C. Mandal, K. Bose, and S. Kozieł, "Impact of social class on body fatness among rural pre-school Bengalee Hindu children of Arambagh, West Bengal, India," Homo: Journal of Comparative Human Biology, vol. 62, no. 3, pp. 228-236, 2011.

[39] V. Mathad, C. Metgud, and M. D. Mallapur, "Nutritional status of under-fives in rural area of South India," Indian Journal of Medical Sciences, vol. 65, no. 4, pp. 151-156, 2011.

[40] J. Sen and N. Mondal, "Socio-economic and demographic factors affecting the Composite Index of Anthropometric Failure (CIAF)," Annals of Human Biology, vol. 39, no. 2, pp. 129-136, 2012.

[41] K. A. Patel, S. D. Langare, J. D. Naik, and S. S. Rajderkar, "Gender inequality and bio-social factors in nutritional status among under five children attending anganwadis in an urban slum of a town in Western Maharashtra, India," Journal of Research in Medical Sciences, vol. 18, no. 4, pp. 341-345, 2013.

[42] R. Anuradha, R. Sivanandham, S. D. Salome et al., "Nutritional status of children aged 3-6 years in a rural area of Tamilnadu," Journal of Clinical and Diagnostic Research, vol. 8, no. 10, pp. JC01-JC04, 2014.

[43] K. Chatterjee, R. K. Sinha, A. K. Kundu et al., "Social determinants of inequities in under-nutrition (weight-for-age) among under-5 children: a cross sectional study in Gumla district of Jharkhand, India," International Journal for Equity in Health, vol. 15, no. 1, article 104, 2016.

[44] J. Sen and S. Ghosh, "Estimation of stature from foot length and foot breadth among the Rajbanshi: an indigenous population of North Bengal," Forensic Science International, vol. 181, no. 1-3, pp. 55.e1-55.e6, 2008.

[45] J. Sen, T. Kanchan, A. Ghosh, N. Mondal, and K. Krishan, "Estimation of stature from lengths of index and ring fingers in a North-eastern Indian population," Journal of Forensic and Legal Medicine, vol. 22, pp. 10-15, 2014.

[46] S. Bisai, K. Bose, and A. Ghosh, "Nutritional status of Lodha children in a village of Paschim Medinipur district, West Bengal," Indian Journal of Public Health, vol. 52, no. 4, pp. 203206, 2008.

[47] S. Ghosh-Jerath, A. Singh, A. Bhattacharya, S. Ray, S. Yunus, and S. P. Zodpey, "Dimensions of nutritional vulnerability: assessment of women and children in Sahariya tribal community of Madhya Pradesh in India," Indian Journal of Public Health, vol. 57, no. 4, pp. 260-267, 2013.

[48] P. Tigga, J. Sen, and N. Mondal, "Association of some socio-economic and socio-demographic variables with wasting among pre-school children of north Bengal, India," Ethiopian Journal of Health Sciences, vol. 25, no. 1, pp. 63-72, 2015.

[49] P. L. Tigga, N. Mondal, and J. Sen, "Effects of certain socioeconomic, socio-demographic and life style factors on the prevalence of thinness among pre-school children of North Bengal, India," Epidemiology of Biostatistics and Public Health, vol. 12, no. 1, Article ID e10282-11, 2015.

[50] P. L. Tigga, N. Mondal, and J. Sen, "Head circumference as an indicator of undernutrition among tribal pre-school children aged 2-5 years of North Bengal, India," Human Biological Review, vol. 5, no. 1, pp. 17-33, 2016. 
[51] K. M. Rao, R. H. Kumar, K. S. Krishna, V. Bhaskar, and A. Laxmaiah, "Diet \& nutrition profile of Chenchu population-a vulnerable tribe in Telangana \& Andhra Pradesh, India," Indian Journal of Medical Research, vol. 141, pp. 688-696, 2015.

[52] S. Islam, T. G. Mahanta, R. Sarma, and S. Hiranya, "Nutritional status of under 5 children belonging to tribal population living in riverine (Char) areas of Dibrugarh district, Assam," Indian Journal of Community Medicine, vol. 39, no. 3, pp. 169-174, 2014.

[53] K. D. Singh, M. Alagarajan, and L. Ladusingh, "What explains child malnutrition of indigenous people of Northeast India?" PLoS ONE, vol. 10, no. 6, article e0130567, 2015.

[54] V. G. Rao, R. Yadav, C. K. Dolla, S. Kumar, M. K. Bhondeley, and M. Ukey, "Undernutrition and childhood morbidities among tribal preschool children," Indian Journal of Medical Research, vol. 122, no. 1, pp. 43-47, 2005.

[55] K. Bhattacharyya and T. K. Sarkar, "Nutritional profile of children under 5 years of age in a tribal community in the District of Maldah, West Bengal," Journal of Primary Care \& Community Health, vol. 1, no. 3, pp. 184-186, 2010.

[56] I. I. Meshram, N. Arlappa, N. Balakrishna, K. Mallikharjuna Rao, A. Laxmaiah, and G. N. V. Brahmam, "Trends in the prevalence of undernutrition, nutrient $\&$ food intake and predictors of undernutrition among under five year tribal children in India," Asia Pacific Journal of Clinical Nutrition, vol. 21, no. 4, pp. 568-576, 2012.

[57] A. Dharmalingam, K. Navaneetham, and C. S. Krishnakumar, "Nutritional status of mothers and low birth weight in India," Maternal and Child Health Journal, vol. 14, no. 2, pp. 290-298, 2010.

[58] J. Sen, A. Roy, and N. Mondal, "Association of maternal nutritional status, body composition and socio-economic variables with low birth weight in India," Journal of Tropical Pediatrics, vol. 56, no. 4, pp. 254-259, 2009.

[59] S. K. Kaushal, S. K. Misra, S. C. Gupta, and R. Singh, "A study of maternal factors and birth weight in a border District of Uttar Pradesh: a hospital based study," Indian Journal of Community Health, vol. 24, no. 2, pp. 86-90, 2012.

[60] M. Borah and R. Agarwalla, "Maternal and socio-demographic determinants of low birth weight (LBW): a community-based study in a rural block of Assam," Journal of Postgraduate Medicine, vol. 62, no. 3, pp. 178-181, 2016.

[61] R. K. Bhadra and S. Chakraborty, "Cultural dimension of health of tea labourers in West Bengal," in Plantation Labours of Northeast India, R. K. Bhadra and M. Bhadra, Eds., pp. 199-212, N.L Publishers, Dibrugarh, India, 1997.

[62] U. Kapil and R. Pradhan, "Integrated Child Development Services scheme (ICDS) and its impact on nutritional status of children in India and recent initiatives," Indian Journal of Public Health, vol. 43, no. 1, pp. 21-25, 1999.

[63] Y. Touitou, F. Portaluppi, M. H. Smolensky, and L. Rensing, "Ethical principles and standards for the conduct of human and animal biological rhythm research," Chronobiology International, vol. 21, no. 1, pp. 161-170, 2004.

[64] J.S. Weiner and J. A. Lourie, Practical Human Biology, Academic Press, London, UK, 1981.

[65] S. J. Ulijaszek and D. A. Kerr, "Anthropometric measurement error and the assessment of nutritional status," British Journal of Nutrition, vol. 82, no. 3, pp. 165-177, 1999.

[66] WHO 2010 WHO, The WHO child growth standards, 2006, http://www.who.int/childgrowth/en/.

[67] The World Health Report, Make Every Mother and Child Count, World Health Organization, Geneva, Switzerland, 2005.
[68] National Family Health Survey (NFHS-2), 1998-99: India, International Institute for Population Sciences (IIPS) and ORC Macro, Mumbai, 2000.

[69] S. Bharati, M. Pal, B. N. Bhattacharya, and P. Bharati, "Prevalence and causes of chronic energy deficiency and obesity in Indian women," Human Biology, vol. 79, no. 4, pp. 395-412, 2007.

[70] K. Bose, S. Bisai, S. Sadhukhan, A. Mukhopadhyay, and M. Bhadra, "Undernutrition among adult Bengalees of Dearah, Hooghly District, West Bengal, India: relationship with educational status and food habit," Anthropologischer Anzeiger, vol. 67, no. 2, pp. 121-128, 2009.

[71] N. Arlappa, K. M. Rao, K. Venkaiah, G. N. V. Brahmam, and K. Vijayaraghavan, "Nutritional parameters and chronic energy deficiency in older adults of desert areas of western Rajasthan, India," Journal of Nutrition for the Elderly, vol. 28, no. 1, pp. 6171, 2009.

[72] B. Bandyopadhyay and D. Sen, "Assessment of energy balance against the nutritional status of women carriers in the brickfields of West Bengal," International Journal of Occupational Safety and Ergonomics, vol. 22, no. 3, pp. 399-404, 2016.

[73] S. Bisai and K. Bose, "Undernutrition in the Kora Mudi tribal population, West Bengal, India: a comparison of body mass index and mid-upper-arm circumference," Food and Nutrition Bulletin, vol. 30, no. 1, pp. 63-67, 2009.

[74] S. Chakrabarty and P. Bharati, "Adult body dimension and determinants of chronic energy deficiency among the Shabar tribe living in urban, rural and forest habitats in Orissa, India," Annals of Human Biology, vol. 37, no. 2, pp. 149-167, 2010.

[75] S. D. Banik, "Nutritional status adiposity and body composition of Oraon and Sarak females in Ranchi District, India-a comparison," Ecology of Food and Nutrition, vol. 50, no. 1, pp. 43-62, 2011.

[76] S. Ghosh, "Deficiency and sources of nutrition among an Indian tribal population," Collegium Antropologicum, vol. 38, no. 3, pp. 847-853, 2014.

[77] R. K. Rai, "Factors associated with nutritional status among adult women in urban India, 1998-2006," Asia-Pacific Journal of Public Health, vol. 27, no. 2, pp. 1241-1252, 2015.

[78] I. Meshram, N. Balakrishna, K. Sreeramakrishna et al., "Trends in nutritional status and nutrient intakes and correlates of overweight/obesity among rural adult women ( $\geq 18-60$ years) in India: National Nutrition Monitoring Bureau (NNMB) national surveys," Public Health Nutrition, vol. 19, no. 5, pp. 767-776, 2016.

[79] G. D. N. Bouzitou, B. Fayomi, and H. Delisle, "Child malnutrition and maternal overweight in same households in poor urban areas of Benin," Cahiers Sante, vol. 15, no. 4, pp. 263-270, 2005.

[80] M. Rahman, S. K. Roy, M. Ali, A. K. Mitra, A. N. Alam, and M. S. Akbar, "Maternal nutritional status as a determinant of child health," Journal of Tropical Pediatrics, vol. 39, no. 2, pp. 86-88, 1993.

[81] M. A. Islam, M. M. Rahman, and D. Mahalanabis, "Maternal and socioeconomic factors and the risk of severe malnutrition in a child: a case-control study," European Journal of Clinical Nutrition, vol. 48, no. 6, pp. 416-424, 1994.

[82] J. L. Santos, J. Kain, P. Dominguez-Vásquez et al., "Maternal anthropometry and feeding behavior toward preschool children: association with childhood body mass index in an observational study of Chilean families," International Journal of Behavioral Nutrition and Physical Activity, vol. 6, article 93, 2009. 
[83] R. A. Kulasekaran, "Influence of mothers' chronic energy deficiency on the nutritional status of preschool children in Empowered Action Group states in India," International Journal of Nutritional Pharmacology Neurological Disorders, vol. 2, no. 3, pp. 198-209, 2012.

[84] C. Fleten, W. Nystad, H. Stigum et al., "Parent-offspring body mass index associations in the Norwegian Mother and Child Cohort Study: a family-based approach to studying the role of the intrauterine environment in childhood adiposity," American Journal of Epidemiology, vol. 176, no. 2, pp. 83-92, 2012.

[85] T. A. Ajslev, L. Ängquist, K. Silventoinen, J. L. Baker, and T. I. A. Sørensen, "Trends in parent-child correlations of childhood body mass index during the development of the obesity epidemic," PLoS ONE, vol. 9, no. 10, article e109932, 2014.

[86] S. Ray, "Growth Pattern of children of two social groups: a longitudinal study," Journal of Human Ecology, vol. 15, no. 1, pp. 31-39, 2004.

[87] M. F. Rolland-Cachera, M. Deheeger, F. Bellisle, M. Sempé, M. Guilloud-Bataille, and E. Patois, "Adiposity rebound in children: a simple indicator for predicting obesity," American Journal of Clinical Nutrition, vol. 39, no. 1, pp. 129-135, 1984. 


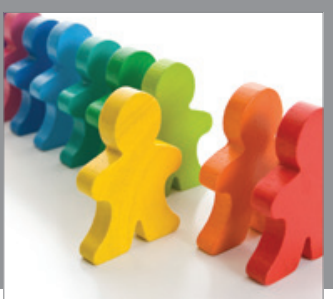

Autism

Research and Treatment
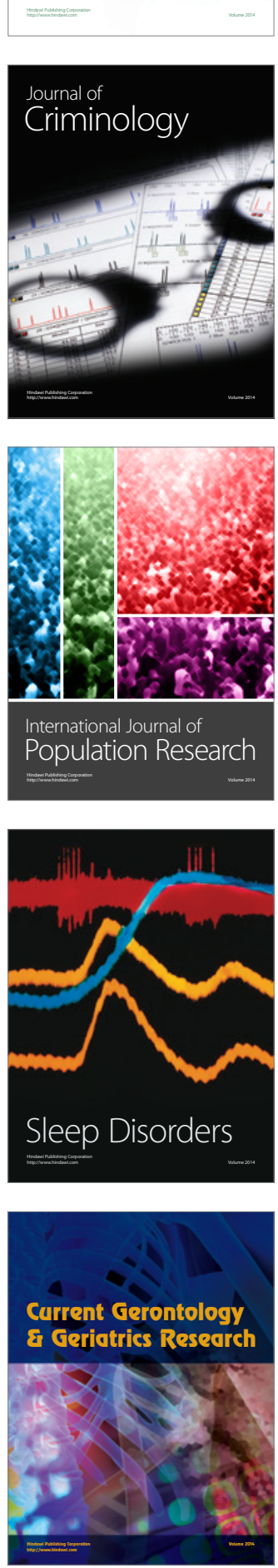

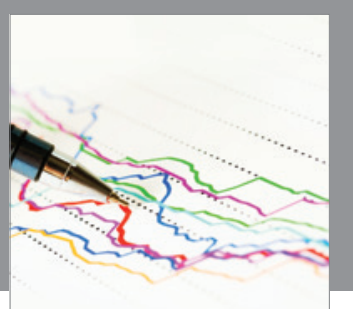

Economics

Research International
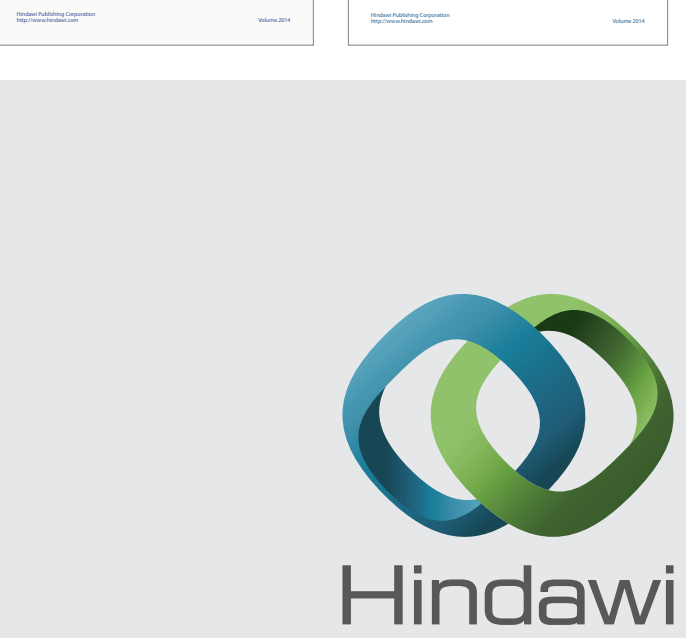

Submit your manuscripts at

http://www.hindawi.com
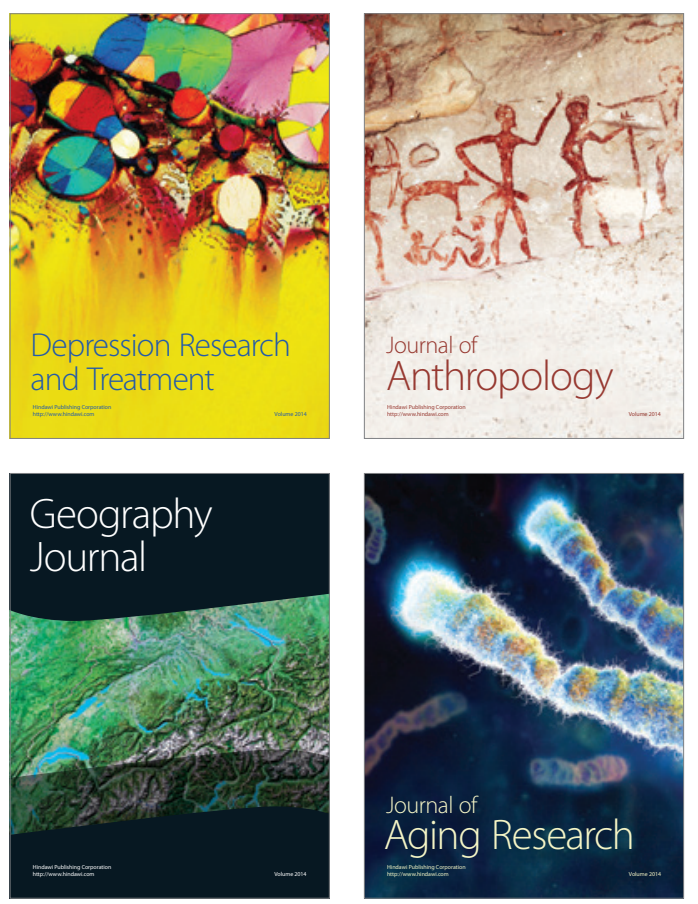
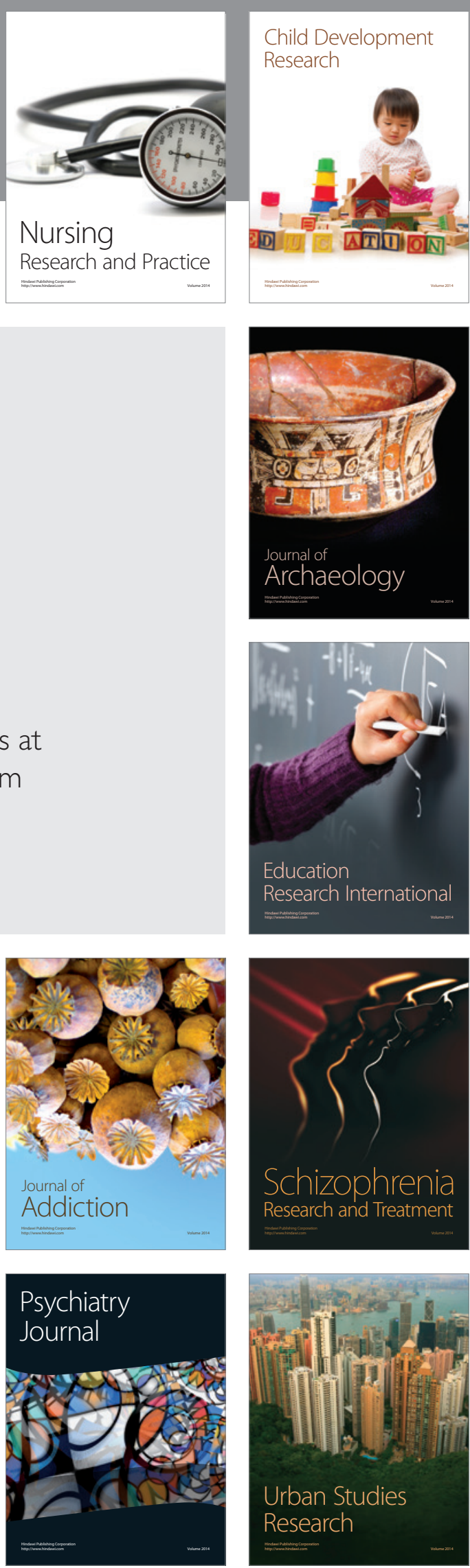